\title{
Magneto-Impedansi pada Kumparan Kawat Fe
}

\author{
Hanafi Eko Prasetyo, Utari, dan Budi Purnama* \\ Jurusan Fisika-FMIPA, Universitas Sebelas Maret (UNS) \\ Jl. Ir. Sutami 36A Kentingan 36A, Surakarta 57126
}

\begin{abstract}
Intisari
Klarifikasi fenomena magneto impedansi pada kumparan kawat Fe dilaporkan pada makalah ini. Fenomena magneto-impedansi pada kumparan kawat $\mathrm{Fe}$ juga telah dikonfirmasi ketergantungannya terhadap jumlah lilitan kawat (N), diameter kumparan (d) dan diameter kawat (D). Peningkatan jumlah lilitan (N) dan diameter kumparan (d) mempercepat laju penurunan nilai L pada kurva respon magneto-impedansi. Sedangkan laju penurunan nilai L berkurang dengan kenaikan diameter kawat kumparan (D). Akhirnya, realisasi respon magneto-impedansi pada frekuensi rendah menegaskan fenomena ini didominasi oleh efek magneto-induksi.
\end{abstract}

\begin{abstract}
Clarification of magneto-impedance on Fe wire solenoid had reported in this paper. The magneto-impedance phenomenon also had confirmed for both a number solenoid (N), solenoid diameter (d) and wire diameter (D) dependence. The increased for both $\mathrm{N}$ and $\mathrm{d}$ trigered the reduced of value $\mathrm{L}$. Meanwhile the reduced of $\mathrm{L}$ became slow with the increased of wire diameter D. Finally, realization of magneto-impedance respons at low frequency indicated that the phenomenon dominated by magneto-inductive effect.
\end{abstract}

KATA KUNCI: magneto-impedance, solenoid, Fe wire

\section{PENDAHULUAN}

Fenomena magneto-impedansi yaitu perubahan nilai impedansi suatu bahan akibat medan magnet luar, merupakan komplemen fenomena magneto-resistansi dan juga menjadi property spintronik yang ditemukan paling akhir. Mengingat karakteristik impedansi sangat bergantung pada frekuensi, maka material magnetik dengan permeabilitas $(\mu)$ tinggi berpotensi sebagai material magneto-impedance [1-4]. Secara umum, magneto impedansi dirumuskan sebagai:

$$
\frac{\Delta Z}{Z}(\%)=\frac{Z(H)-Z(\text { Hmaks })}{Z(\text { Hmaks })} \times 100 \%
$$

Berdasarkan persamaan di atas, maka nilai nisbah magneto impedansi utamanya dipengaruhi 2 faktor yaitu frekuensi dari arus AC yang menyumbang nilai impedansi intrinsik dan medan magnet eksternal H. Sedangkan berkenaan dengan bahan, magneto impedansi terealisasi pada kawat metal amorf (amorphous metallic wires), ribbon metal amorf (amorphous metallic ribbon), magnetic thin film, dan nano crystalline magnetic alloy [5]. Fenomena magneto-impedansi yang dibentuk dari material yang telah disebutkan sebelumnya ini teramati pada devais micro-inductor [5-7]. Mengingat karakteristik dasar induktor maka dimensi divais sangat menentukan nilai impedansi terukur.

Pada makalah ini akan didiskusikan studi pendahuluan magneto-impedansi pada kumparan kawat Fe. Ide ini merupakan enlarge scale micro-wire inductor yaitu memperbe-

\footnotetext{
*E-MAIL: bpurnama@mipa.uns.ac.id
}

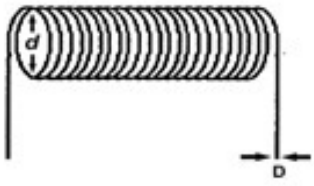

Gambar 1: Kawat dibentuk kumparan.

sar dimensi micro wire inductor hingga berukuran beberapa centimeter. Hal ini akibat keterbatasan fasilitas fabrikasi. Penelitian ini bertujuan untuk mengamati fenomena-magneto impedansi pada kumparan kawat Fe. Selebihnya investigasi pengaruh jumlah lilitan kumparan $(\mathrm{N})$, pengaruh diameter kawat (D), dan pengaruh diameter kumparan (d) terhadap magneto-impedansi yang terukur.

\section{METODE EKSPERIMEN}

Sampel yang digunakan pada penelitian ini adalah kumparan kawat Fe dengan jumlah lilitan adalah $\mathrm{N}$, diameter kumparan adalah d dan diameter kawat adalah D (Gambar 1). Sampel yang telah diperoleh kemudian rangkai sesuai dengan Gambar 2 untuk diukur nilai impedansinya. LCR meter yang digunakan adalah GW Instek LCR-819. Kumparan pembangkit medan magnet buatan sendiri dengan core berupa besi teknis diameter 3 inci. Kawat kumparan yang digunakan berdiameter $0,35 \mathrm{~mm}$ dan jumlah lilitan masing-masing kumparan pembangkit medan magnet adalah 5000 lilitan.

Prinsip magneto impedansi adalah perubahan nilai impedansi suatu bahan pada saat dialiri arus AC akibat 


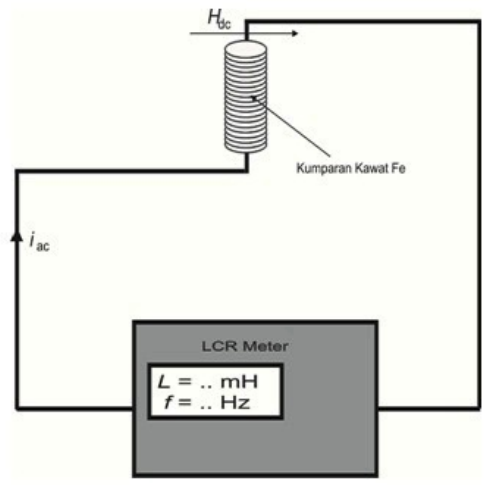

Gambar 2: Setup alat percobaan.

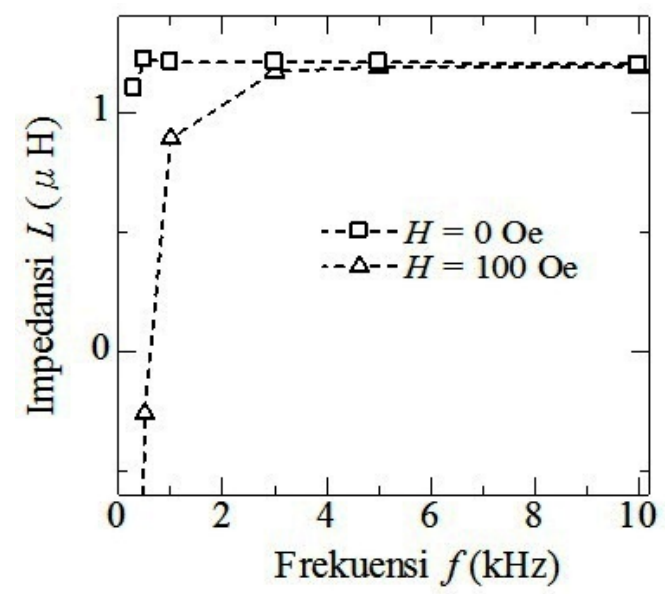

Gambar 3: Kurva ketergantungan impedansi L dengan frekuensi diukur untuk $\mathrm{H}=0$ dan $\mathrm{H}=100$ Oe.

pengaruh medan magnet luar $\mathrm{H}$. Untuk memperoleh modifikasi nilai impedansi, maka sampel divariasi $\mathrm{N}$, d, dan D. Jumlah lilitan kumparan divariasi $\mathrm{N}=10,20$, dan 30 lilitan, diameter kumparan ditetapkan untuk $\mathrm{d}=1,0 \mathrm{~cm}$ dan $1,5 \mathrm{~cm}$, dan untuk variasi diameter kawat dipakai $\mathrm{D}=0,2$ $\mathrm{mm}$ dan $0,08 \mathrm{~mm}$. Hasil yang diperoleh diplot kurva dan dianalisis ketergantungan magneto-impedansinya terhadap varibel-varibel penelitian.

\section{HASIL DAN PEMBAHASAN}

Kurva impedansi sebagai fungsi frekuensi untuk $\mathrm{H}=0$ Oe dan $\mathrm{H}=100 \mathrm{Oe}$, diperlihatkan oleh Gambar 3. Terlihat dengan jelas bahwa medan magnet sangat berpengaruh untuk menurunkan nilai impedansi L kumparan kawat besi terutama pada frekuensi kurang dari $3 \mathrm{kHz}$. Lebih lanjut, tipikal penurunan nilai $\mathrm{L}$ oleh medan magnet ditunjukkan pada frekuensi $300 \mathrm{~Hz}$. Pada keadaan medan magnet belum terpasang $\mathrm{H}=0$ Oe nilai $\mathrm{L}=1,1 \mu \mathrm{H}$, dan nilai $\mathrm{L}=-2,89 \mu \mathrm{H}$ ketika medan magnet $\mathrm{H}=100$ Oe. Selisih nilai impedansi $\eta=3,99 \mu \mathrm{H}$ diperoleh untuk dua kedaan pengukuran impedansi dengan medan magnet berbeda. Tipikal perubahan impedansi akibat pengaruh

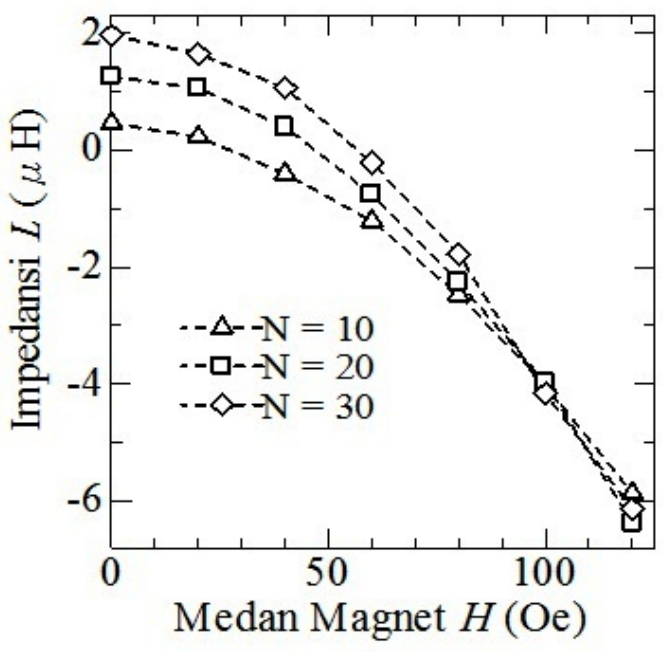

Gambar 4: Kurva L sebagai fungsi $\mathrm{H}$ untuk variasi jumlah lilitan yaitu $\mathrm{N}=10,20$ dan 30 pada $\mathrm{f}=300 \mathrm{~Hz}$.

medan magnet dikenal sebagai fenomena magneto-impedansi [7-9]. Realisasi fenomena magneto-impedansi pada range frekuensi rendah ini menegaskan bahwa mekanisme magnetoinduktif mendominasi perubahan nilai impedansi yang terukur [5].

Kurva impedansi sebagai fungsi medan magnet untuk variasi jumlah lilitan kumparan yaitu $\mathrm{N}=10,20$, dan 30 dievaluasi pada frekuensi $300 \mathrm{~Hz}$, diperlihatkan dalam Gambar 4 . Keseluruhan sampel memperlihatkan penurunan nilai L dengan kenaikan medan magnet. Dibawah pengaruh medan magnet nol, peningkatan jumlah lilitan meningkatkan nilai $\mathrm{L}$ sampel. Berturut-turut nilai $\mathrm{L}=0,46 \mu \mathrm{H}$ untuk $\mathrm{N}=10, \mathrm{~L}=$ $1,26 \mu \mathrm{H}$ untuk $\mathrm{N}=20$, dan $\mathrm{L}=1,97 \mu \mathrm{H}$ untuk $\mathrm{N}=30$. Ketika medan magnet dinaikkan, nilai $\mathrm{L}$ menurun. Teramati dari kurva bahwa laju penurunan nilai impedansi untuk jumlah lilitan $\mathrm{N}=30$ lebih cepat dibandingkan sampel lain. Hal ini dapat dikorelasikan dengan sifat magnetik sampel kumparan. Jika kumparan ditinjau sebagai sistem soft magnetik maka peningkatan jumlah lilitan akan menguatkan karakter soft magnetik kumparan dengan indikator respon terhadap medan magnet. Kenyataan ini terungkap penurunan nilai $\mathrm{L} \propto 6 \mathrm{H}$ pada $\mathrm{H}=100$ Oe dari mula-mula untuk sampel $\mathrm{N}$ $=30$ dibandingkan lainnya.

Kurva impedansi sebagai fungsi medan magnet $\mathrm{H}$ untuk variasi diameter kawat besi kumparan yaitu $\mathrm{D}=0,2 \mathrm{~mm}$ dan $\mathrm{D}=0,08 \mathrm{~mm}$ diukur pada frekuensi $300 \mathrm{~Hz}$, diperlihatkan oleh Gambar 5. Terlihat pada Gambar 5 bahwa besar nilai $\mathrm{D}$ yang digunakan berpengaruh terhadap penurunan nilai impedansi. Pada $\mathrm{H}=0$ Oe, nilai impedansi kumparan kawat Fe untuk $\mathrm{D}=0,2 \mathrm{~mm}$ adalah $0,46 \mu \mathrm{H}$ sedangkan untuk D $=0,08 \mathrm{~mm}$ impedansi terukur $\mathrm{L}=0,43 \mu \mathrm{H}$. Konsisten dengan hasil pengukuran sebelumnya bahwa nilai impedansi $\mathrm{L}$ kumparan dibawah pengaruh medan magnet eksternal $\mathrm{H}=$ 120 Oe menurun menjadi $-5,87 \mathrm{mH}$ (untuk $\mathrm{D}=0,2 \mathrm{~mm}$ ), dan nilai $\mathrm{L}$ kumparan dengan $\mathrm{D}=0,08 \mathrm{~mm}$ adalah $-8,70 \mu \mathrm{H}$. Data tersebut memperlihatkan dengan jelas diameter kawat (D) lebih kecil memperlihatkan penurunan nilai L yang lebih 


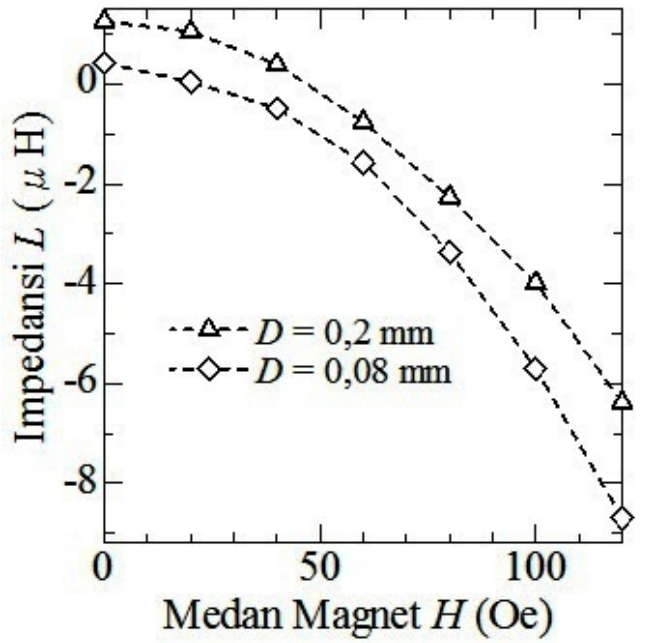

Gambar 5: Kurva $L$ versus $H$ untuk variasi diameter kawat kumparan $\mathrm{D}=0,2 \mathrm{~mm}$ dan $\mathrm{D}=0,08 \mathrm{~mm}$ pada $\mathrm{f}=300 \mathrm{~Hz}$.

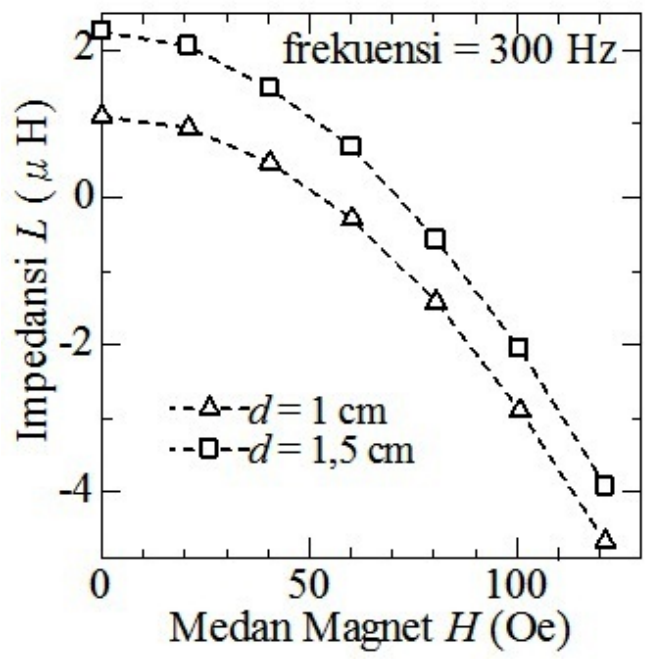

Gambar 6: Kurva $\mathrm{L}$ sebagai fungsi $\mathrm{H}$ untuk modifikasi diameter kumparan $\mathrm{d}=1 \mathrm{~cm}$ dan $\mathrm{d}=1,5 \mathrm{~cm}$ pada $\mathrm{f}=300 \mathrm{~Hz}$ cepat dibandingkan diameter kawat (D) lebih besar.

Modifikasi nilai impedansi kumparan kawat Fe lainnya ditunjukkan Gambar 6. Kurva tersebut memperlihatkan nilai impedansi kumparan kawat Fe sebagai fungsi medan magnet untuk dua variasi diameter kumparan kawat besi yaitu $\mathrm{d}=1 \mathrm{~cm}$ dan $\mathrm{d}=1,5 \mathrm{~cm}$. Evaluasi nilai impedansi dilakukan pada frekuensi $300 \mathrm{~Hz}$. Aspek lain ketergantungan magneto-impedansi kumparan kawat dengan diameter kumparan terungkap pada gambar tersebut. Pada $\mathrm{H}=0$ Oe, nilai impedansi kumparan kawat diameter $1 \mathrm{~cm}$ adalah $1,1 \mu \mathrm{H}$ dan turun menjadi $-4,67 \mu \mathrm{H}$ ketika medan magnet terpasang $\mathrm{H}=120$ Oe. Perubahan nilai $\mathrm{L}$ akibat medan magnet adalah $5,77 \mu \mathrm{H}$. Sedangkan nilai impedansi kumparan kawat diameter $1,5 \mathrm{~cm}$ adalah $2,25 \mathrm{H}$ dan merosot hingga $\mathrm{L}=-3,92 \mathrm{H}$ dibawah pengaruh medan magnet $\mathrm{H}=120$ Oe dengan nilai perubahan L sebesar 6,17 $\mu \mathrm{H}$. Kenyataan hasil ini menegaskan bahwa semakin besar diameter kumparan kawat maka respon magneto-impedansi yang didapat akan semakin besar. Hal ini sesuai dengan hasil penelitian yang telah dipublikasikan $\mathrm{Hu}$ dkk [10].

\section{SIMPULAN}

Perubahan nilai impedansi kumparan kawat Fe akibat pengaruh medan magnet eksternal (magneto-impedansi) telah berhasil diklarifikasi. Fenomena magneto-impedansi pada kumparan kawat $\mathrm{Fe}$ juga telah dikonfirmasi ketergantungannya terhadap jumlah lilitan kawat $(\mathrm{N})$, diameter kawat (D), dan diameter kumparan (d). Peningkatan jumlah lilitan (N) dan diameter kumparan (d) mempercepat laju penurunan nilai L pada kurva respon magneto-impedansi. Laju penurunan nilai L berkurang dengan kenaikan diameter kawat kumparan (D).
[1] G.V. Kurlyandskaya, et al., Applied Physics Letters., 82, 30533055 (2003).

[2] L.V. Panina, et al., Journal of Applied Physics.,76, 6198-6203 (1993).

[3] K. Mohri, et al., IEEE Trans. Magn., 29, 1245-1248 (1993).

[4] R.S. Beach, et al., Appl. Phys. Lett., 68, 2753 (1996).

[5] M.H. Phan and H.X. Peng., Progress in Materials Science., 53, 323-420 (2008)
[6] K. Mohri, et al., Sensors and Actuators A, 91, 85-90 (2001)

[7] M.H. Phan, et al., Journal of applied physics, 97, 10M108.

[8] V. Raposo, et al., Journal of Optoelectronics and Advanced Materials, 6, 575-580 (2004)

[9] C. Sirisathitkul and P. Jantaratana, J. Mater.Sci.Technol., 25, 825-828 (2009).

[10] J. Hu, et al., J. Appl. Phys., 91, 7418 (2002). 